\title{
Knowledge on Prevention of Cerebro Vascular Accident among Patients with Diabetes and Hypertension in India
}

\author{
Dr. Helen Shaji John Cecily \\ Assistant professor, Nursing Department, College of Applied Medical Sciences, Majma'ah University, KSA
}

\begin{abstract}
Background:- Meeting the need for knowledge relating to the nature of stroke and risk factors for stroke is still a substantial challenge in the World. Lack of knowledge about stroke in general and specific knowledge of the risk factors, signs, and symptoms of stroke results in the late presentation of patients at hospital. The result is delay in prompt initiation of stroke management and noncompliance with follow-up rehabilitation. So there is a need to empower people to take control of their own health. The study was aimed to investigate the level of knowledge of stroke among diabetes and hypertension patients regarding cerebrovascular accident and to find out the association between the level of knowledge of patients on cerebrovascular accident and their selected demographic variables. Methodology:- A descriptive quantitative design using a cross-sectional survey was used to collect data. The sample comprised of 70 patients with Diabetes mellites or hypertension and who met the inclusion criteria were selected for the study using simple random sampling method. Results:- The findings revealed that only 8 patients (11.43\%) had adequate knowledge and 32 (45.71\%) had inadequate knowledge on prevention of CVA. The variables like age, sex, marital status, educational status, occupation, monthly family income, duration of illness and duration of treatment had significant association with the level of knowledge at $P<0.05$ level. Conclusion:- This study has created an awareness about the necessity of planning health education programmes on focussing this risk group for CVA. Education and support can help the diabetes and hypertensive patients to take necessary measures to have control over their Blood sugar and blood pressure levels inorder to prevent the complication of CVA.
\end{abstract}

Keywords: Knowledge, cerebrovascular accident, Diabetes mellites, hypertension, awareness.

\section{Introduction}

\author{
"Save your brain from disease \\ Wave bye to the carpits of hypertension. \\ Self help is the best help. \\ A disease known is half cured."
}

Chronic disease impairs the bodily structure or functions and necessitates the modification of the person's normal life; cerebrovascular disease is not an exception. The term "brain attack" is being used to suggest to health care practitioners and the public that a stroke is an urgent health care issue as heart attack. Early treatment results in fewer symptoms and less loss of function.

\section{The global burden of stroke}

Every year, 15 million people worldwide suffer a stroke. Nearly six million die and another five million are left permanently disabled. Stroke is the second leading cause of disability, after dementia. Disability may include loss of vision and / or speech, paralysis and confusion.Globally, stroke is the second leading cause of death above the age of 60 years, and the fifth leading cause of death in people aged 15 to 59 years old. ${ }^{1}$

Developing countries like India are facing a double burden of communicable and non-communicable diseases. Stroke is one of the leading causes of death and disability in India. The estimated adjusted prevalence rate of stroke range, 84$262 / 100,000$ in rural and 334-424/100,000 in urban areas. The incidence rate is $119-145 / 100,000$ based on the recent population based studies. ${ }^{2}$
High blood pressure, also known as hypertension, is the single most important risk factor for stroke. It causes about 50 per cent of ischemic strokes and also increases the risk of hemorrhagic stroke. The damage that hypertension causes happens over time and is often only diagnosed when considerable damage has already happened to the body's blood vessels. ${ }^{1}$ If you have diabetes, your chances of having a stroke are 1.5 times higher than in people who don't have diabetes. But you can lower your risk by taking care of your health. ${ }^{3}$

Hypertension, diabetes mellitus, smoking, dyslipidemia, atrial fibrillation, and sickle cell disease are well documented risk factors for stroke. ${ }^{4}$

A study done in the USA by Beckera, Fruina, Goodinga et al. (2001) found that baseline knowledge about stroke among the public is poor and the knowledge deficit was greatest among Asian-Americans, men, the less educated and low-income residents. ${ }^{5}$ In a study done in Spain, Seguraa, Vegab, Lópezc, Rubiod \& Castilloe (2003) confirmed that the community was still unfamiliar with stroke. ${ }^{6}$ Studies shows that public knowledge of stroke warning signs and risk factors is limited, with persons at greatest risk of stroke including the elderly who have the least knowledge (Greenlund, Neff, Zheng et al., 2003; Flaherty, Kleindorfer, \& Kissela, 2004; Carroll, Hobart, Fox et al., 2004) ${ }^{7}$.

The researcher acknowledges the fact that it is very important for the patients to know the risk factors of stroke, failure to which they may not engage in prevention practices such as proper following of medication regimes, regular medical checkup, change of lifestyles including smoking 


\section{International Journal of Science and Research (IJSR) \\ ISSN (Online): 2319-7064}

Index Copernicus Value (2013): 6.14 | Impact Factor (2014): 5.611

cessation, stopping excessive alcohol intake, and avoiding sedentary life and poor diet.

Further, the researcher recognizes that unless patients are made aware of the signs and symptoms of stroke, they will postpone early hospital presentation which decreases recovery chances. These patients may also not willingly engage in post stroke rehabilitation programs. The researcher was therefore motivated to embark on this study by the above realizations. The aim was to investigate the level of knowledge of stroke among diabetes and hypertension patients as it will assist in the establishment of health education and health promotion programs, which in turn will raise the stroke awareness among the target society, and hence facilitate early hospital presentation and positive response to post stroke management and follow-up rehabilitation.

\section{Objectives}

1) To assess the level of knowledge of Diabetes and hypertensive clients regarding cerebrovascular accident

2) To find out the association between the level of knowledge of patients on cerebrovascular accident and their selected demographic variables.

\section{Methodology}

\section{Research Design}

A descriptive quantitative design using a cross-sectional survey was used to collect data in the present study.

\section{Setting of the study}

The study was conducted in Government hospital, Chrompet, Chennai, India. It is a 200 bedded hospital, consisting of an Out patient Department to treat patients with Hypertension and Diabetes mellites. The OPD functions from 8.30 A.M to 12.00 noon and there are about 120 patients attending the OPD daily. Out of this, on an average 30 - 40 patients are Diabetic or hypertensive. There are nine wards in the in-patient departments. Each ward consists of $15-20$ beds.

\section{Sample and Sampling Techniques}

The sample of the study comprised of 70 patients with Diabetes mellites or hypertension and who met the inclusion criteria were selected for the study using simple random sampling method.

\section{Criteria for Selection of Sample Inclusive criteria}

- Patients who were diagnosed as having Diabetes mellites or hypertension by a qualified Medical officer.

- Patients who were admitted in the ward as well as the OPD.

- Men and women patients who could understand Tamil or English

- Patients above 30 years of age.

\section{Exclusion Criteria}

- Patients who were taken for pilot study

- Patients who were diagnosed as Cerebro vascular accident

\section{Content Validity}

The tool was submitted to experts of Medical and Surgical Nursing to establish content validity.

\section{Description of the instrument:}

The study was conducted by using structured interview schedule. The Instrument consists of two sections.

PART - A: Demographic variables which includes age , sex, marital status, educational status, occupation, monthly family income, duration of illness and duration of treatment.

PART - B: Structured knowledge questionnaire was used to assess the knowledge regarding prevention of CVA among patients with hypertension and Diabetes mellites.

Total 25 Multiple Choice Questions were taken and each question has 1 correct response and the total score was 25 .

\section{Score Interpretation}

The score was interpreted as follows:

Below 50\% - Inadequate knowledge

$50 \%$ - 75\% - Moderately adequate knowledge

Above 75 \% - Adequate knowledge

\section{Data Collection Procedure}

Before starting the data collection, researcher obtained permission from the Chief Superintendant of Medical Officer (CSMO) in Chrompet General Hospital and the informed consent was obtained from the participants. The sample were selected based on the inclusion criteria.

Total 70 patients were selected through simple random sampling technique and the study was conducted for a period of two weeks. The first part of the Demographic data was completed after which the second part of the data collection regarding the knowledge on CVA was completed using interview method. The patient's response was marked by the investigator. An information booklet on prevention of CVA was issued to all the participants once the investigator completed the data collection.

\section{Results}

\section{Demographic Variables of the Patients}

The results reveal that, majority (71\%) of the patients were above 50 years old and most $(68.57 \%)$ of them were females. Regarding the marital status, $90 \%$ of them were married and $50 \%$ of them had studied upto High school level and $42.86 \%$ studied upto primary level. Majority of the patients 56 (79.47\%) were doing daily wages and their monthly income was Rs. 3000 to 4000 . More than $50 \%$ of the patients had either Diabetes or hyertension for more than 3 years. Regarding the duration of treatment, 33(47.14\%) were on treatment for above 3 years, 8 (11.43\%) had on treatment less than one year. 


\section{International Journal of Science and Research (IJSR) \\ ISSN (Online): 2319-7064 \\ Index Copernicus Value (2013): 6.14 | Impact Factor (2014): 5.611}

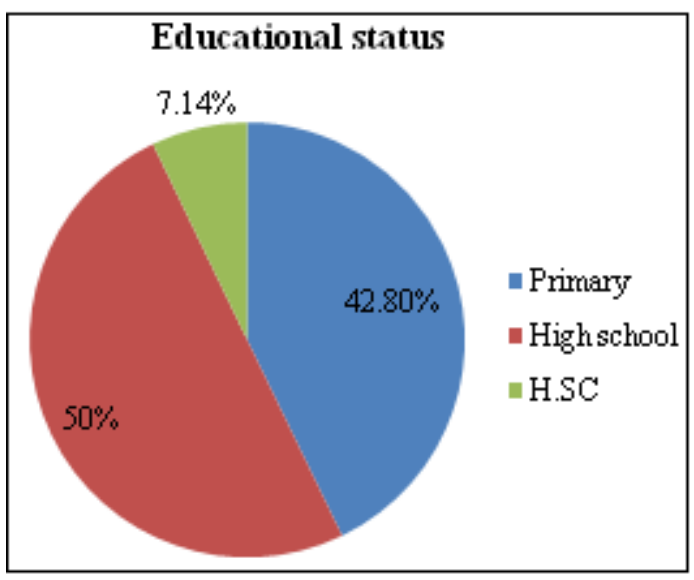

Figure 1: Educational status of the patients with Diabetes / Hypertension

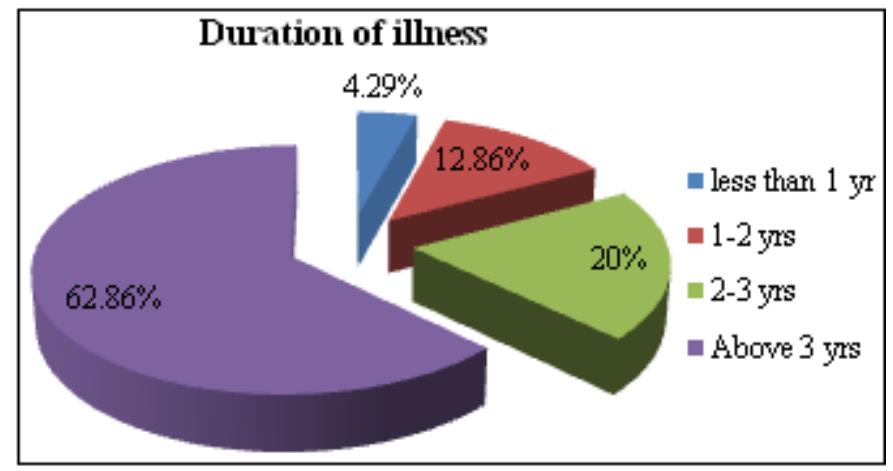

Figure 2: Duration of illness

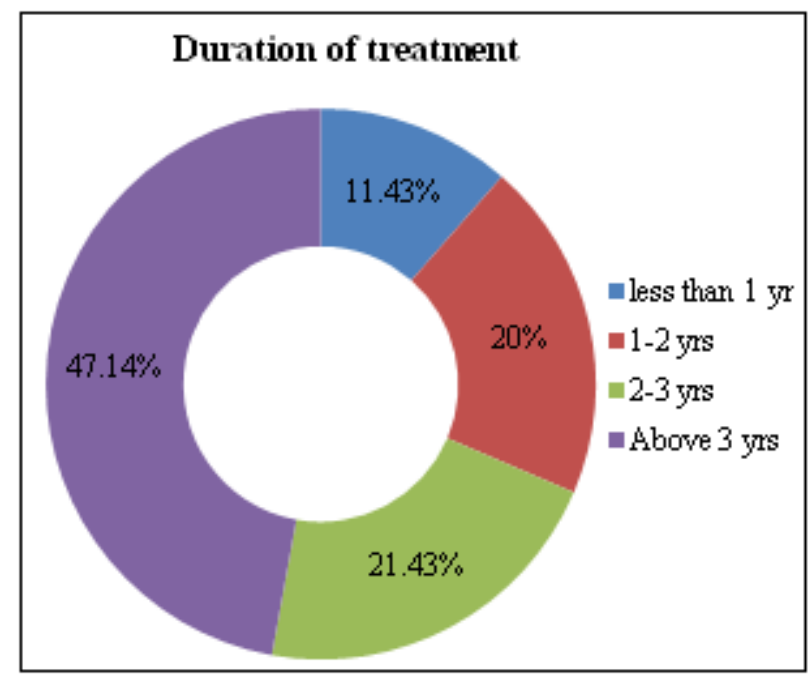

Figure 3: Duration of Treatment for Diabetes / Hypertension

Table 1: Level of Knowledge on prevention of CVA among patients with Diabetes or Hypertension

\begin{tabular}{|c|c|c|c|}
\hline S. No & Level of Knowledge & Frequency & Percentage (\%) \\
\hline 1 & Adequate & 8 & 11.43 \\
\hline 2 & Moderately adequate & 30 & 42.86 \\
\hline 3 & Inadequate & 32 & 45.71 \\
\hline
\end{tabular}

From table. 1, it is revealed that only 8 patients (11.43\%) had adequate knowledge and 32 (45.71\%) had inadequate knowledge on prevention of CVA. So there is an urgent need to plan for health education on prevention of CVA for High risk group patients.
Table 2: Association between the level of knowledge on prevention of CVA among patients with Diabetes /

Hypertension and their selected demographic variables

\begin{tabular}{|c|c|c|c|c|}
\hline S. No & Demographic variable & Frequency & $\begin{array}{c}\text { Percentage } \\
(\%)\end{array}$ & $\begin{array}{c}\text { Chi square } \\
\text { value }\end{array}$ \\
\hline 1 & \begin{tabular}{|l} 
Age \\
$30-40$ years \\
$41-50$ years \\
$51-60$ years \\
Above 61 years \\
\end{tabular} & $\begin{array}{l}7 \\
13 \\
24 \\
26\end{array}$ & $\begin{array}{l}10 \\
18.57 \\
34.28 \\
37.14\end{array}$ & $\begin{array}{l}\mathrm{X} 2=5.52 \\
\mathrm{P}<0.05 \\
\text { Significant }\end{array}$ \\
\hline 2 & \begin{tabular}{|l|} 
Sex \\
Male \\
Female \\
\end{tabular} & $\begin{array}{l}22 \\
48 \\
\end{array}$ & $\begin{array}{l}31.43 \\
68.57\end{array}$ & $\begin{array}{l}\mathrm{X} 2=0.463 \\
\mathrm{P}<0.05 \\
\text { Significant }\end{array}$ \\
\hline 3 & $\begin{array}{l}\text { Marital status } \\
\text { Married } \\
\text { Unmarried } \\
\text { Widow/ widower }\end{array}$ & $\begin{array}{l}63 \\
2 \\
5\end{array}$ & $\begin{array}{l}90 \\
2.86 \\
7.14\end{array}$ & $\begin{array}{l}\mathrm{X} 2=1.86 \\
\mathrm{P}<0.05 \\
\text { Significant }\end{array}$ \\
\hline 4 & \begin{tabular}{|l} 
Education \\
Primary school \\
High school \\
Higher secondary \\
Degree
\end{tabular} & $\begin{array}{l}30 \\
35 \\
5 \\
0\end{array}$ & $\begin{array}{l}42.86 \\
50 \\
7.14 \\
0\end{array}$ & $\begin{array}{l}\mathrm{X} 2=2.90 \\
\mathrm{P}<0.05 \\
\text { Significant }\end{array}$ \\
\hline 5 & $\begin{array}{l}\text { Occupation } \\
\text { Govt. employee } \\
\text { Private employee } \\
\text { Coolie } \\
\text { Unemployed }\end{array}$ & $\begin{array}{l}5 \\
9 \\
43 \\
13\end{array}$ & $\begin{array}{l}7.14 \\
12.86 \\
61.4 \\
18.57\end{array}$ & $\begin{array}{l}\mathrm{X} 2=1.95 \\
\mathrm{P}<0.05 \\
\text { Significant }\end{array}$ \\
\hline 6 & $\begin{array}{l}\text { Income } \\
\text { Rs. } 3000-4000 \\
\text { Rs. } 4000-6000 \\
\text { Above } 6000\end{array}$ & $\begin{array}{l}55 \\
12 \\
3\end{array}$ & \begin{tabular}{|l}
78.57 \\
17.14 \\
4.29
\end{tabular} & $\begin{array}{l}\mathrm{X} 2=2.57 \\
\mathrm{P}<0.05 \\
\text { Significant }\end{array}$ \\
\hline 7 & $\begin{array}{l}\text { Duration of illness } \\
<1 \text { year } \\
1-2 \text { years } \\
2-3 \text { years } \\
>3 \text { years }\end{array}$ & $\begin{array}{l}3 \\
9 \\
14 \\
44 \\
\end{array}$ & $\begin{array}{l}4.29 \\
12.86 \\
20 \\
62.86\end{array}$ & $\begin{array}{l}\mathrm{X} 2=4.006 \\
\mathrm{P}<0.05 \\
\text { Significant }\end{array}$ \\
\hline 8 & $\begin{array}{l}\text { Duration of treatment } \\
<1 \text { year } \\
1-2 \text { years } \\
2-3 \text { years } \\
>3 \text { years }\end{array}$ & $\begin{array}{l}8 \\
14 \\
15 \\
33\end{array}$ & $\mid \begin{array}{l}11.43 \\
20 \\
21.43 \\
47.14\end{array}$ & $\begin{array}{l}\mathrm{X} 2=2.71 \\
\mathrm{P}<0.05 \\
\text { Significant }\end{array}$ \\
\hline
\end{tabular}

From table.2, it is evident that there is a significant association between the level of knowledge and the selected demographic variables like age , sex, marital status, educational status, occupation, monthly family income, duration of illness and duration of treatment at $\mathrm{P}<0.05$ level.

\section{Discussion}

The first objective was to assess the level of knowledge regarding prevention of Cerebro Vascular Accident among patients with Diabetes mellites or hypertension. Regarding overall categorization, from selected 70 samples, only 8 patients $(11.43 \%)$ had adequate knowledge and 32 (45.71\%) had inadequate knowledge on prevention of CVA. So there is an urgent need to plan for health education on prevention of CVA for High risk group patients.

This is further supported by findings of Kadumukkasa $M$ et al (2015) conducted a cross sectional study on Knowledge, attitudes and perceptions of stroke rural and urban Uganda. Through the systematic sampling method, data were gathered from 377 adult participants who were interviewed about selected aspects of stroke knowledge, attitudes and 


\section{International Journal of Science and Research (IJSR) \\ ISSN (Online): 2319-7064}

Index Copernicus Value (2013): 6.14 | Impact Factor (2014): 5.611

perception using a pretested structured questionnaire. The results showed $76 \%$ of the participants did not recognize stroke as a disease of the brain. So they concluded that a tailored public health approaches that improve stroke awareness, knowledge and self management approaches are urgently needed to develop effective preventive measures and community response to stroke. ${ }^{8}$

The second objective was to find the association between the level of knowledge regarding prevention of CVA among patients with Diabetes or Hypertension and their selected demographic variables. The variables like age , sex, marital status, educational status, occupation, monthly family income, duration of illness and duration of treatment had significant association with the level of knowledge at $\mathrm{P}<$ 0.05 level.

The above findings are supported by the study conducted by John Joseph Tesha (2006) on Knowledge of stroke among hypertensive patients in Tanzania, who reported that the participant's overall knowledge of stroke was significantly associated with age, education level, employment, and participants' occupation. The young participants (25-50 years) were more knowledgeable about stroke than their counterparts. The participants who had college level of education scored higher on knowledge of stroke than participants who had other levels of education. The employed scored higher than unemployed participants on the question of knowledge of stroke. Likewise, participants in health related occupations had more knowledge about stroke than the participants from other occupations. ${ }^{9}$

\section{Implications}

- Nurses working in medical ward are needed to assess the knowledge regarding CVA among hypertension and diabetes mellites patients.

- Periodic health camps can be conducted by the Public health nurses in the communities which will help them to plan for health education programmes about prevention of cerebrovascular accidents among people who had risk factors as well as to impart knowledge on warning signs of CVA.

\section{Conclusion}

As there are only limited studies on knowledge of CVA among patients with Diabetes mellites and Hypertension in india, this study has created an awareness about the necessity of planning health education programmes on focussing this risk group for CVA. Education and support can help the diabetes and hypertensive patients to take necessary measures to have control over their Blood sugar and blood pressure levels inorder to prevent the complication of CVA.

\section{References}

[1] http://www.world-heart-federation.org/cardiovascularhealth/stroke/ retrieved on 18.03.2016

[2] Jeyaraj Durai Pandian and Paulin Sudhan Stroke Epidemiology and Stroke Care Services in India J Stroke. 2013 Sep; 15(3): 128-134.
[3] http://www.diabetes.org/living-withdiabetes/complications/heartdisease/stroke.html?referrer=https://www.google.com.sa/ (American Diabetes association)

[4] Goldstein LB, Adams R, Becker K, et al. Primary prevention of ischemic stroke: a statement for healthcare professionals from the stroke council of the American Heart Association. Circulation. 2001;103:163-182

[5] Beckera, K.J., Fruina, M.S., Goodinga, T.D., Tirschwella, D.L., Lovea, P.J., Mankowskia, T.M. (2001). Community-Based Education Improves Stroke Knowledge. Journal of Cerebrovascular Diseases, (11), 34-43.

[6] Seguraa, T., Vegab, G., Lópezc, S., Rubiod, F., Castilloe, J. (2003). Public Perception of Stroke in Spain. Journal of Cerebrovascular Diseases, (16), 21-26.

[7] Greenlund, K.J., Neff, L.J., Zheng, Z.J., Keenan, N.L., Giles, W.H., Ayala, C.A., Croft, J.B., Mensah, G.A. (2003). Low public recognition of major stroke symptoms. American Journal of Preventive Medicine, 25 (4), 315-319.

[8] Kaddumukasa $\mathrm{M}^{1}$, Kayima $\mathrm{J}^{2}$, Kaddumukasa $\mathrm{MN}^{3}$, Ddumba $E^{4}$, Mugenyi $L^{5}$, Pundik $S^{6}$, Furlan $\mathrm{AJ}^{7}$, Sajatovic $\mathrm{M}^{8}$, Katabira $\mathrm{E}$ Knowledge, attitudes and perceptions of stroke: a cross-sectional survey in rural and urban Uganda BMC Res Notes. 2015 Dec 26;8(1):819. doi: 10.1186/s13104-015-1820-6.

[9] John Joseph Tesha, Knowledge of stroke among hypertensive patients in selected hospitals in the Tanga Region, Tanzania .A mini-thesis submitted to the Faculty of Community and Health Sciences of the University of the Western Cape, November 2006 